\title{
The selective Hsp90 inhibitor BJ-B11 exhibits potent antitumor activity via induction of cell cycle arrest, apoptosis and autophagy in Eca-109 human esophageal squamous carcinoma cells
}

\author{
KAI-SHENG LIU ${ }^{1,2^{*}}$, YI ZHANG ${ }^{1 *}$, WEI-CHAO DING ${ }^{1}$, SHAO-XIANG WANG $^{1}$, YANG-FEI XIANG ${ }^{1}$, \\ PAN YANG $^{1}$, ZHEN-PING CHEN ${ }^{1}$, KAI ZHENG ${ }^{1}$, ZHONG LIU $^{1}$, MIN XIA ${ }^{1}$ and YI-FEI WANG ${ }^{1}$ \\ ${ }^{1}$ Institute of Biomedicine, ${ }^{2}$ College of Pharmacy, Jinan University, Guangzhou 510632, P.R. China
}

Received July 30, 2012; Accepted September 3, 2012

DOI: 10.3892/ijo.2012.1670

\begin{abstract}
BJ-B11 is a selective heat shock protein 90 (Hsp90) inhibitor that has been reported to possess significant antitumor activity in multiple types of cancer cells; however, the mechanism of action needs to be further clarified. We investigated, for the first time, the antitumor activity and the molecular mechanism underlying growth inhibition in Eca-109 cells. The results revealed that BJ-B11 inhibited the proliferation of Eca-109 cells in a time- and concentration-dependent manner, with $50 \%$ inhibitory concentration $\left(\mathrm{IC}_{50}\right)$ values of $0.31 \pm 0.01 \mu \mathrm{M}$ after 48-h incubation. BJ-B11 induced concentration-dependent G2/M cell cycle arrest and apoptosis. The cleavage of caspase 3 and PARP signals detected might originate from mitochondrial dysfunction, which was supported by the results of reactive oxygen species (ROS) production, cytochrome $c$ release and the mitochondrial membrane potential (MMP) reduction. The general caspase inhibitor Z-VAD-fmk did not completely abolish BJ-B11-induced cell death. Furthermore, inhibition of the Akt/ mTOR/p70S6K signaling pathway might be involved in the process of BJ-B11-induced autophagy, which was characterized by the production of autophagic vacuoles and upregulation of LC3-II protein in a time- and concentration-dependent manner. Meanwhile, the general autophagy inhibitor 3-MA decreased the apoptotic ratio. Furthermore, BJ-B11 induced the polymerization of cytoskeleton $\beta$-tubulin and F-actin. Taken together, our results suggest that the growth inhibition of Eca-109 cells induced by BJ-B11 may result from the induction of G2/M cell cycle arrest, apoptosis and autophagy.
\end{abstract}

\section{Introduction}

Hsp90 is a molecular chaperone that is responsible for the stability and function of over 100 client proteins (1). Hsp90

Correspondence to: Dr Yi-Fei Wang, Institute of Biomedicine, Jinan University, Guangzhou 510632, P.R. China

E-mail: twang-yf@163.com

*Contributed equally

Key words: heat shock protein 90 inhibitor, BJ-B11, cell cycle, apoptosis, autophagy, cytoskeleton client proteins include Akt, IKK $\alpha$, B-Raf and GSK3 $\beta$, which are critical for the cell survival and proliferation (2). Hsp90 represents $1-2 \%$ of total cellular protein, and is overexpressed 2- to 10-fold in tumor cells compared to normal cells in the same or related tissue (3). In addition, tumor cells are more dependent on Hsp90 than normal counterparts, suggesting that Hsp90 may be important for tumor cell growth or survival (4). The therapeutic efficacy of Hsp90 inhibitors probably relates to the increased levels of active Hsp90 in tumors (5). The Hsp90 inhibitors have been shown to accumulate in tumor tissue while being rapidly cleared in normal tissue and shutdown multiple signaling pathways probably because of the degradation of client proteins (6), and the inhibition of signaling pathways, such as the IKK $\alpha / \mathrm{NF}-\kappa \mathrm{B}$ signaling pathway, may induce apoptosis.

Hsp90 is intimately associated with autophagy (7) and the Hsp90 inhibitor 17-DMAG induces autophagy via the inhibition of mTOR signaling (8). Autophagy is a physiological process regulated by the Akt/mTOR and MAPK/Erk1/2 signaling pathways, which are important in the induction of tumor cell death $(9,10)$. Autophagy is an important cellular response to stress or starvation. Many studies have focused on the importance of autophagy in cancer, however, it is still under debate whether autophagy suppresses tumorigenesis or promotes cell survival $(11,12)$.

Currently, 14 unique chemical moieties are undergoing clinical trials as potential cancer therapeutics (1). 17-AAG, a derivative of geldanamycin, is the first Hsp90 inhibitor to undergo clinical testing and possesses encouraging biological and pharmacologic properties (13). However, the poor pharmaceutical properties such as aqueous solubility and formulation difficulties are anticipated to limit its further clinical development (14), and this has catalyzed the efforts of identifying the novel scaffolds with improved pharmacological and lower toxicity profiles. Thus, novel synthetic Hsp90 inhibitors based on diverse chemical scaffolds have been developed (15).

The novel Hsp90 inhibitor SNX-2112 can selectively bind to the ATP/ADP binding pocket of Hsp90 and is more pharmacologically effective than 17-AAG (16). Also, SNX-2112 is highly effective against various cancer cells in vitro and in vivo $(17,18)$. We have previously reported that SNX-2112 induces apoptosis and/or autophagy in K562, MCF-7 and A375 cell lines 
$(16,19,20)$. In addition, we also analyzed the pharmacokinetics of SNX-2112 in rats with a sensitive and specific reversed-phase high-performance liquid chromatography method $(21,22)$.

BJ-B11 is a novel analog of SNX-2112, and has a structure that differs in the cyclohexanol and inazolone moieties (23). Previous research has shown that BJ-B11 potently induces growth inhibition of a diverse range of tumor cell lines in vitro. However, the molecular mechanism by which BJ-B11 acts needs to be further elaborated.

In this study, we provide the first evidence that BJ-B11 induces growth inhibition, G2/M cell cycle arrest, the mitochondrialmediated apoptosis, autophagy via the inhibition of Akt/mTOR/ p70S6K signaling and cytoskeleton polymerization in Eca-109 cells.

\section{Materials and methods}

Cell culture and reagents. The Eca-109 cells (Cell Bank of the Chinese Academy of Sciences, Shanghai, China) were cultured in RPMI-1640 containing 10\% heat inactivated fetal bovine serum (FBS) and $100 \mathrm{U} / \mathrm{ml}$ penicillin/streptomycin in a humidified incubator in a $5 \% \mathrm{CO}_{2}$ atmosphere at $37^{\circ} \mathrm{C}$.

BJ-B11 was synthesized as previously described with a purity of $>98.0 \%$ (24), and $10 \mathrm{mmol} / \mathrm{l} \mathrm{BJ}-\mathrm{B} 11$ stock solutions in dimethylsulfoxide (DMSO) were stored at $-20^{\circ} \mathrm{C}$. 17-AAG was purchased from Alexis Biochemicals (San Diego, CA). The 3-(4,5-diethylthiazol-2-yl)-2,5-diphenyl tetrazolium bromide (MTT) assay, 4',6-diamidino-2-phenylindole (DAPI), jasplakinolide (Jas), latrunculin A (Lat-A), paclitaxel (PT) and vincristine (VCR) were purchased from Sigma (St. Louis, MO, USA). The mitochondrial membrane potential assay kit with JC-1, Annexin V-FITC/PI staining kit and 2',7'-Dichlorofluorescin diacetate (DCFH-DA) were purchased from Beyotime (Haimen, China). Z-VAD-fmk and the LC3 antibody were purchased from MBL (Japan). Antibodies against cleaved caspase 3, PARP, $\beta$-actin, Akt, p-mTOR, p-p70S6K, p-4EBP1, and p-S6 were purchased from Cell Signaling Technology (Beverly, MA, USA). Antibodies against cytochrome $c$ were purchased from Santa Cruz Biotechnology (Santa Cruz, CA, USA).

MTT. Cells (3x103/well) were plated in 96-well plates in $100 \mu \mathrm{l}$ media, cultured overnight and exposed to a range of concentrations of BJ-B11 (or 17-AAG) for 24,48 or $72 \mathrm{~h}$. After the addition of $20 \mu \mathrm{l}$ of $5 \mathrm{mg} / \mathrm{ml}$ MTT solution/well, the plates were incubated for $4 \mathrm{~h}$, the media were removed, the formazan crystals were solubilized in $100 \mu \mathrm{l} \mathrm{DMSO} /$ well and the absorbance values were read at $570 \mathrm{~nm}$.

Cell cycle analysis. Cells were exposed to the indicated concentrations of BJ-B11 for $48 \mathrm{~h}$, harvested in cold PBS, fixed in $70 \%$ ethanol, stored overnight at $4^{\circ} \mathrm{C}$, washed twice with PBS, resuspended in $50 \mu \mathrm{g} / \mathrm{ml}$ PI staining reagent containing $100 \mu \mathrm{g} /$ $\mathrm{ml}$ RNase and $0.1 \%$ Triton X-100 for $30 \mathrm{~min}$ in the dark. Cells were analyzed by flow cytometry (Becton-Dickinson, CA) and the percentage of cells in the different phases of the cell cycle was analyzed with Becton-Dickinson software.

Annexin V-FITC/PI analysis. Cells were exposed to the indicated concentrations of BJ-B11 for $48 \mathrm{~h}$, harvested, washed twice with ice cold PBS, resuspended in $500 \mu \mathrm{l}$ incubation buffer containing
Annexin V-FITC and PI, incubated in the dark for 15 min and analyzed by flow cytometry.

DAPI staining assay. Cells were exposed to $0.5 \mu \mathrm{M}$ BJ-B11, washed twice in ice-cold PBS, fixed in $4 \%$ paraformaldehyde for $15 \mathrm{~min}$ at room temperature, washed with ice-cold PBS, stained with $5 \mu \mathrm{g} / \mathrm{ml}$ DAPI for 10-15 min and examined by fluorescence microscopy.

Transmission electron microscopy (TEM). Cells were exposed to $0.5 \mu \mathrm{M}$ BJ-B11 for $48 \mathrm{~h}$, harvested, washed twice in ice-cold PBS, and then fixed with ice-cold $2.5 \%$ glutaraldehyde overnight at $4{ }^{\circ} \mathrm{C}$. The samples were post-fixed with $1 \% \mathrm{OsO}_{4}$ in the same buffer for $1 \mathrm{~h}$ and then subjected to electron microscopic analysis. Representative areas were chosen for ultra-thin sectioning and were observed with a Philips Technai-10 transmission electron microscope (Philips Eindhoven, The Netherlands).

Determination of intracellular ROS. Cells were exposed to $0.5 \mu \mathrm{M}$ BJ-B11 for the indicated time periods, harvested, incubated with $10 \mu \mathrm{M}$ DCFH-DA for $15 \mathrm{~min}$ at $37^{\circ} \mathrm{C}$. The fluorescence intensity of cells was measured by flow cytometry with an excitation wavelength of $488 \mathrm{~nm}$ and an emission wavelength of $525 \mathrm{~nm}$.

Evaluation of the MMP. Cells were exposed to $0.5 \mu \mathrm{M}$ BJ-B11 for the indicated time periods, harvested, resuspended in $500 \mu \mathrm{l}$ PBS containing $10 \mu \mathrm{g} / \mathrm{ml}$ of JC- 1 dye, incubated for $15 \mathrm{~min}$ at $37^{\circ} \mathrm{C}$, immediately centrifuged to remove the supernatant, resuspended in PBS and analyzed by flow cytometry. The loss of MMP was quantified as the percentage of cells expressing JC-1 monomer fluorescence.

MDC staining. Cells were exposed to BJ-B11 with or without 3-MA for $48 \mathrm{~h}$, harvested, washed twice in ice-cold PBS, and cultured with $0.05 \mathrm{mM} \mathrm{MDC}$ at $37^{\circ} \mathrm{C}$ for $60 \mathrm{~min}$. The cellular fluorescence intensity was analyzed by flow cytometry.

Immunofluorescence assay. Cells were cultured and treated on glass cover-slips for indicated time periods, fixed in fresh 4\% paraformaldehyde in PBS for 15 min at room temperature, permeabilized with $0.1 \%$ Triton X-100 for $20 \mathrm{~min}$, blocked with $5 \%$ bovine serum albumin (BSA) for $1 \mathrm{~h}$, incubated with $\beta$-tubulin antibody [Alexa Fluor (R) 647 Conj.] (1:500) for $1 \mathrm{~h}$ or Phalloidin for $40 \mathrm{~min}$, respectively, washed three times in PBST. Nuclei were counterstained using $5 \mu \mathrm{g} / \mathrm{ml}$ DAPI for 15 min and the cells were washed, mounted and examined by laser scanning confocal microscopy (LSM510 Meta Duo Scan, Zeiss, Germany).

Western blotting. Cells were exposed to $0.5 \mu \mathrm{M}$ BJ-B11 for indicated time periods, harvested, washed twice in ice-cold PBS, lysed in RIPA buffer for $30 \mathrm{~min}$ on ice, centrifuged at 14,000 $\mathrm{g}$ for $15 \mathrm{~min}$ and the supernatants were collected. Equivalent amounts of lysate (20-30 $\mu \mathrm{g})$ were denatured in SDS sample buffer, resolved on 6-15\% SDS-PAGE gels, transferred to PVDF membranes, blocked in 5\% skimmed milk in Tris-buffered saline (TBS) containing 0.1\% Tween-20 at room temperature for $1 \mathrm{~h}$ and probed with appropriate dilutions (1:100-1:5,000) of primary 

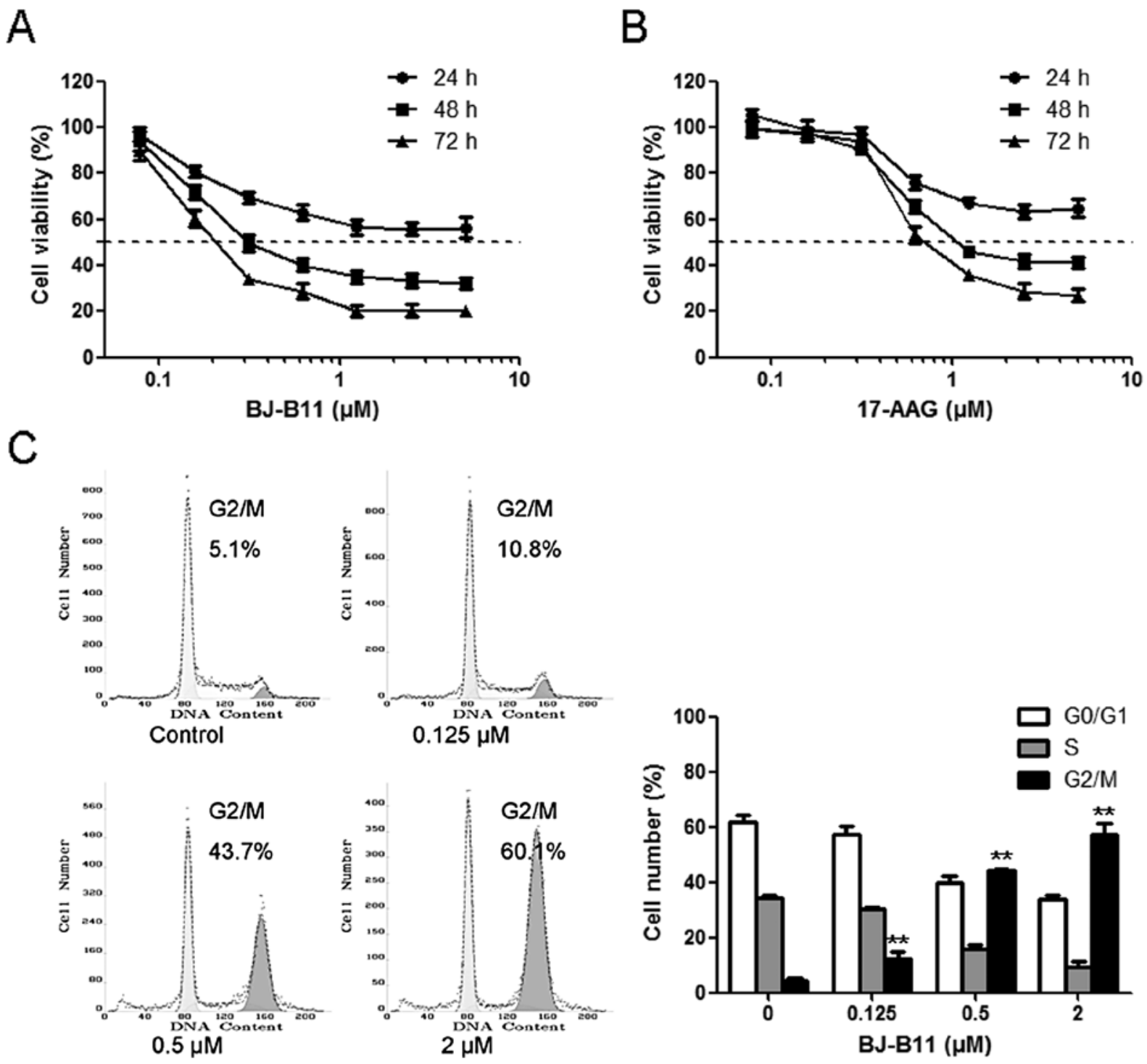

Figure 1. BJ-B11 induces growth inhibition and cell cycle arrest in Eca-109 cells. Eca-109 cells were treated with various concentrations of BJ-B11 (A) or 17-AAG (B) for 24,48 or $72 \mathrm{~h}$ and cell viability was assessed using the MTT assay. (C) Eca-109 cells were treated with various concentrations of BJ-B11 for $48 \mathrm{~h}$ and cell cycle distribution was analyzed by flow cytometry. Values are the mean $\pm \mathrm{SD}$ of three independent experiments; ${ }^{*} \mathrm{P}<0.05$ and ${ }^{* *} \mathrm{P}<0.01$ compared to the untreated control cells.

antibody overnight at $4^{\circ} \mathrm{C}$. The membranes were washed three times in TBST for 5 min, incubated with secondary antibody $(1: 3,000)$ for $1 \mathrm{~h}$ at room temperature, washed and the bound antibodies were detected using an enhanced chemiluminescence kit (Haimen) following the manufacturer's instructions.

Statistical analysis. Data are expressed as the means \pm SD. Differences between two groups were analyzed using the Student's t-test and groups of three or more were analyzed using One-way ANOVA multiple comparisons. ${ }^{*} \mathrm{P}<0.05$ and ${ }^{* *} \mathrm{P}<0.01$ were considered statistically significant.

\section{Results}

BJ-B11 induces growth inhibition and cell cycle arrest in Eca-109 cells. Initially, we assessed the effects of BJ-B11 and 17-AAG on the growth of Eca-109 cells using MTT assay. Eca-109 cells were cultured in the presence of increasing concentrations of BJ-B11 (or 17-AAG) for 24,48 or $72 \mathrm{~h}$. Both BJ-B11 and 17-AAG inhibited Eca-109 cell growth in a time- and concentration-dependent manner with the $\mathrm{IC}_{50}$ values of $0.31 \pm 0.01$ and $1.10 \pm 0.02 \mu \mathrm{M}$ following 48-h incubation, respectively (Fig. 1A and B).

To investigate the mechanism by which cell growth was inhibited, the cell cycle progression was examined by flow cytometry. BJ-B11 treatment resulted in the accumulation of cells in the G2/M phase, with a concomitant reduction in the proportion of cells in the G0/G1 and S phase in a concentrationdependent manner (Fig. 1C). The percentage of cells in the G2/M phase increased to $12.45 \pm 2.33,44.20 \pm 0.71$ and $57.30 \pm 3.96 \%$ at a concentration of $0.125,0.5$ and $2 \mu \mathrm{M}$, respectively.

BJ-B11 induces caspase-dependent apoptosis in Eca-109 cells. To confirm whether BJ-B11 induced cell death occurred via apoptosis, we examined the ability of BJ-B11 to induce the characteristic morphological changes of apoptosis with DAPI staining and TEM. As shown in Fig. 2A and B, marked 
A

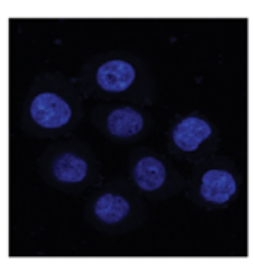

Control

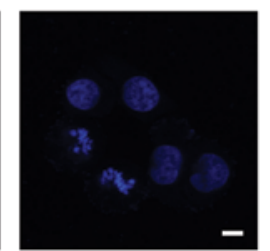

BJ-B11
B

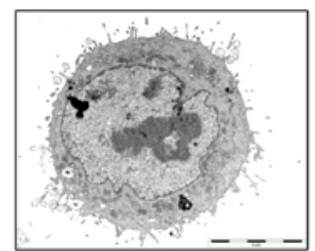

Control

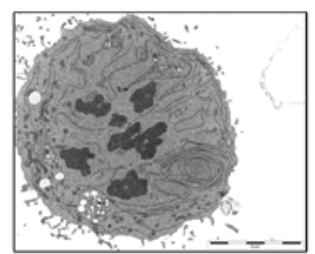

BJ-B11

C
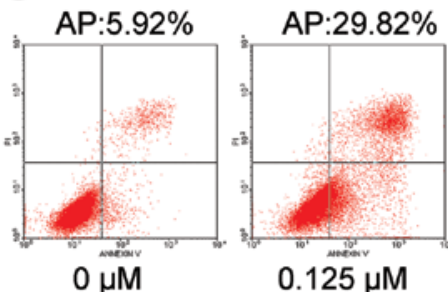

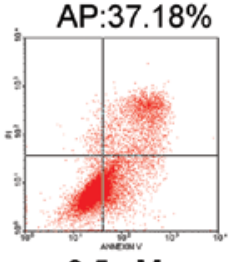

$0.5 \mu \mathrm{M}$

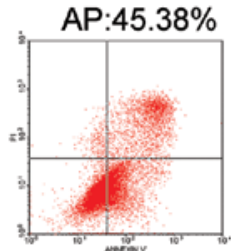

$2 \mu \mathrm{M}$

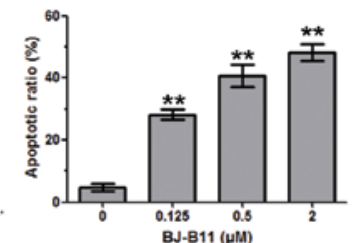

D

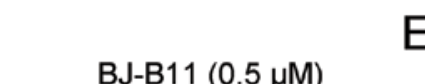

E
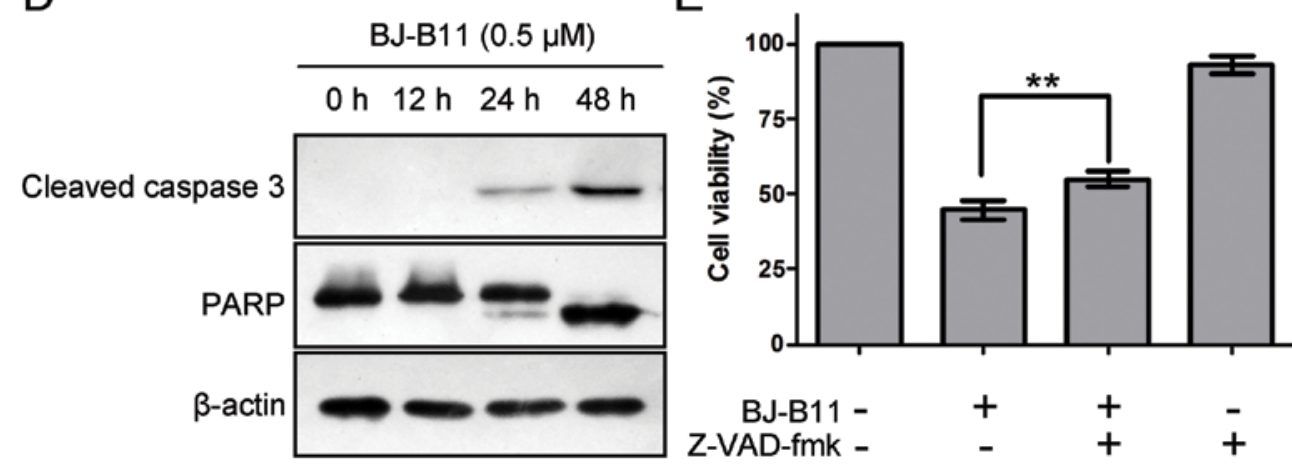

Figure 2. BJ-B11 induces apoptosis in Eca-109 cells. Eca-109 cells were treated with $0.5 \mu \mathrm{M} \mathrm{BJ-B11}$ for $48 \mathrm{~h}$, and morphological changes observed using DAPI staining (scale bars, $10 \mu \mathrm{m})(\mathrm{A})$ and TEM (scale bars, $5 \mu \mathrm{m})(\mathrm{B})$. (C) Quantification of the apoptotic rate in control and BJ-B11-treated Annexin V-FITC/PI stained cells at $48 \mathrm{~h}$. Values are the mean \pm SD of three independent experiments; ${ }^{*} \mathrm{P}<0.05$ and ${ }^{* *} \mathrm{P}<0.01$. (D) Western blot analysis of cleaved caspase 3 and PARP expression in Eca-109 cells treated with $0.5 \mu \mathrm{M}$ BJ-B11. $\beta$-actin was used as a loading control. (E) Quantification of cell viability in cells pretreated with $25 \mu \mathrm{M}$ Z-VAD-fmk for 30 min prior to treatment with $0.5 \mu \mathrm{M}$ BJ-B11 for $48 \mathrm{~h}$. Values are the mean $\pm \mathrm{SD}$ of three independent experiments; "P<0.05 and ${ }^{* * *} \mathrm{P}<0.01$.

morphologic alterations indicative of apoptosis such as nuclear condensation, chromatin marginalization, and DNA fragmentation were observed in cells treated with $0.5 \mu \mathrm{M}$ BJ-B11 for $48 \mathrm{~h}$.

To further investigate whether BJ-B11 induced growth inhibition was due to apoptosis, we performed the Annexin-V FITC/ PI double staining analysis. As shown in Fig. 2C, BJ-B11 induced significant apoptosis in a concentration-dependent manner, and the rate of early apoptotic and late apoptotic cells and necrotic cell death in Eca-109 cells increased markedly to $28.19 \pm 1.63$, $40.68 \pm 3.50$ and $48.14 \pm 2.76 \%$ at a concentration of $0.125,0.5$ and $2 \mu \mathrm{M}$, respectively.

Next, we examined the effects of BJ-B11 on caspase activity to determine whether caspase activation occurs in the BJ-B11-induced apoptosis. Western blot analysis indicated that treatment of Eca-109 cells with $0.5 \mu \mathrm{M}$ BJ-B11 for 0, 12, 24 and $48 \mathrm{~h}$ resulted in cleavage of caspase 3 and PARP (Fig. 2D). The cleavage of caspases plays a key role in the process of apoptotic cell death (25). We therefore wondered whether the inhibition of caspases with the general caspase inhibitor Z-VAD-fmk would prevent BJ-B11 induced cell death. As shown in Fig. 2E, pretreat- ment of cells with $25 \mu \mathrm{M} Z$-VAD-fmk significantly improved the cell viability as assessed by MTT assay, indicating that the cell death induced by BJ-B11 is caspase-dependent.

BJ-B11 induces mitochondrial dysfunction in Eca-109 cells. To investigate whether mitochondria were involved in the mechanism of BJ-B11-induced apoptosis, we evaluated the production of ROS, the release of cytochrome $c$, and the reduction of MMP. As shown in Fig. 3A, treatment of Eca-109 cells with $0.5 \mu \mathrm{M}$ BJ-B11 resulted in significant production of ROS, which increased to $1.33 \pm 0.10$-fold of control at $12 \mathrm{~h}$. BJ-B11 induced the release of cytochrome $c$ into the cytosol of Eca-109 cells in a time-dependent manner (Fig. 3B). It is well established that apoptotic stimuli alter the MMP (26). We examined the MMP by JC-1 staining. As shown in Fig. 3C, BJ-B11 induced significant reduction of MMP after treatment of Eca-109 cells for $48 \mathrm{~h}$. These results suggested that mitochondrial dysfunction was involved in the BJ-B11-induced apoptosis.

BJ-B11 induces autophagy via inhibition of Akt/mTOR/p70S6K signaling in Eca-109 cells. As the pretreatment of Z-VAD-fmk 
A

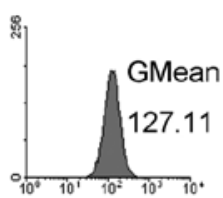

$\mathrm{Oh}$

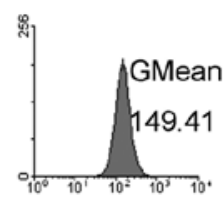

$6 \mathrm{~h}$

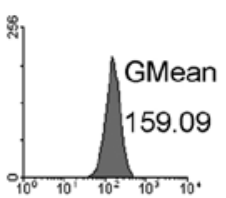

$12 \mathrm{~h}$

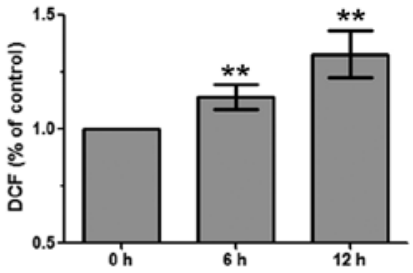

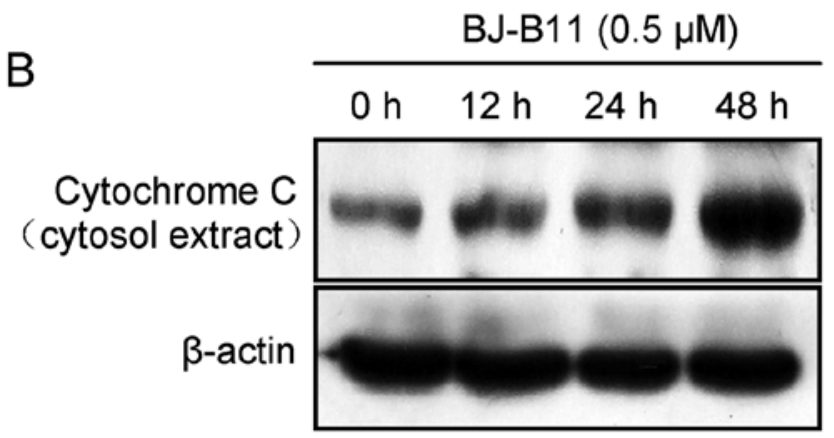

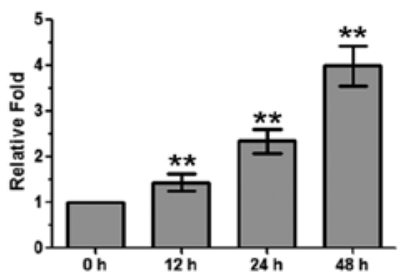

C

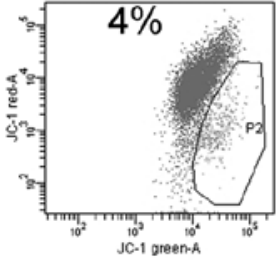

$\mathrm{Oh}$

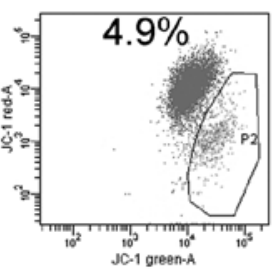

$12 \mathrm{~h}$

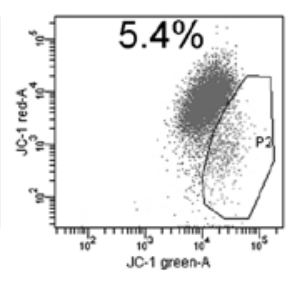

$24 \mathrm{~h}$

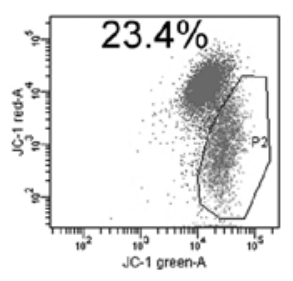

$48 \mathrm{~h}$

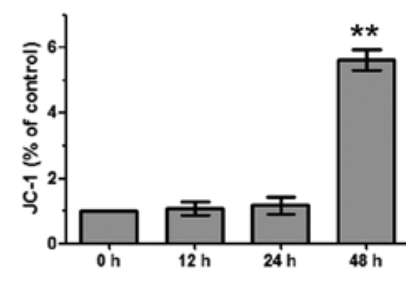

Figure 3. BJ-B11 induces mitochondrial dysfunction in Eca-109 cells. Eca-109 cells were treated with $0.5 \mu \mathrm{M}$ BJ-B11 for the indicated times. (A) DCF was measured by flow cytometry. (B) Cytosolic cytochrome $c$ levels were analyzed by western blotting. $\beta$-actin was used as a loading control. (C) Representative flow cytometric analyses of MMP in BJ-B11 treated cells; increased JC-1 expression indicates reduced MMP. Values are the mean \pm SD of three independent experiments; ${ }^{*} \mathrm{P}<0.05$ and ${ }^{* *} \mathrm{P}<0.01$.

could only increase part of the cell viability, we next investigated whether BJ-B11 induced autophagy in Eca-109 cells. Treatment of Eca-109 cells with $0.5 \mu \mathrm{M}$ BJ-B11 resulted in autophagic vacuoles (Fig. 4A and B), revealed by TEM and monodansylcadaverine (MDC) staining. We also examined the levels of LC3-II induced by BJ-B11 treatment, since this protein is a good indicator of autophagosome formation (27). As shown in Fig. 4B and C, BJ-B11 induced punctate redistribution and cleavage of LC3 in a time- and concentration-dependent manner. Specifically, treatment of Eca-109 cells with $0.5 \mu \mathrm{M} \mathrm{BJ}-\mathrm{B} 11$ resulted in the fluorescence intensity of MDC-positive vacuoles increased to $1.37 \pm 0.15$-fold than that of control, which could be inhibited by the pretreatment of the general autophagy inhibitor 3-MA (Fig. 4D). We next evaluated the ratio of apoptotic cells induced by BJ-B11 with or without 3-MA. As shown in Fig. 4E, pretreatment of Eca-109 cells with 3-MA could significantly reduce the ratio of apoptotic cells induced by BJ-B11, indicating that autophagy promoted apoptosis.

Akt/mTOR/p70S6K signaling pathway plays a key role in regulating autophagy (28). We next examined the role of Akt/ mTOR/p70S6K in BJ-B11-induced autophagy. As shown in Fig. 4F, treatment with BJ-B11 reduced the expression of Akt, p-mTOR, p-p70S6K, p-4EBP1 and p-S6. These results suggest that BJ-B11 may induce autophagy via Akt/mTOR/p70S6K signaling inhibition in Eca-109 cells.
BJ-B11 induces $\beta$-tubulin and F-actin polymerization in Eca-109 cells. As reported, the polymerization or depolymerization of tubulin and F-actin are related with the induction of $\mathrm{G} 2 / \mathrm{M}$ cell cycle arrest, apoptosis, and autophagy (29-32). To evaluate whether BJ-B11 interferes with cytoskeleton network, we examined its effects on $\beta$-tubulin and F-actin by laser scanning confocal microscopy. Paclitaxel (microtubule polymerizing agent) and vincristine (microtubule depolymerizing agent) was used as positive or negative control, respectively. BJ-B11 induced $\beta$-tubulin polymerization at 12,24 and $48 \mathrm{~h}$, respectively, with an increased density of cellular microtubules and formation of long thick microtubule bundles surrounding the nucleus, which was similar to the effects with paclitaxel treatment (Fig. 5A). Fig. 5B shows that BJ-B11 induced polymerization of F-actin at 12, 24 and $48 \mathrm{~h}$, respectively. Jas inducing the polymerization and stabilization of actin filaments and Lat-A preventing actin polymerization, were used as controls. Furthermore, to quantify the polymerization, we next analyzed the fluorescence intensity by flow cytometry. As shown in Fig. 5C, BJ-B11 increased $\beta$-tubulin to $1.34 \pm 0.19$-fold of the control at $24 \mathrm{~h}$, whereas, BJ-B11 increased F-actin to $1.47 \pm 0.19$-fold of the control at $24 \mathrm{~h}$ (Fig. 5D). These results indicate that the growth inhibition of Eca-109 cells induced by BJ-B11 may also be associated with the cytoskeleton polymerization. 
A

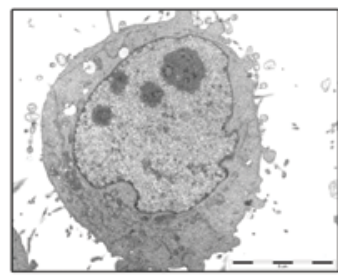

Control

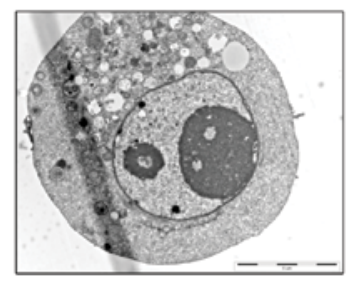

BJ-B11
C

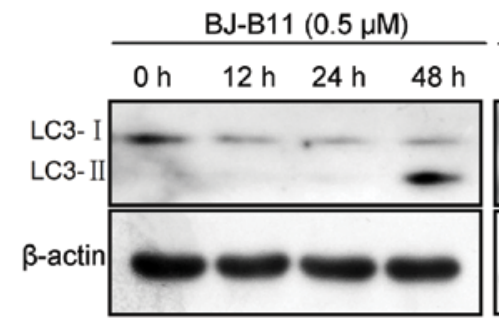

D
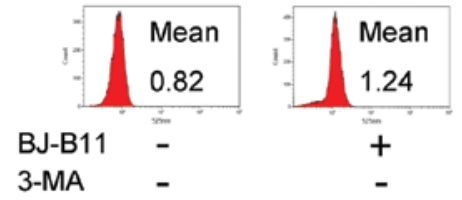

$+$

3-MA

E
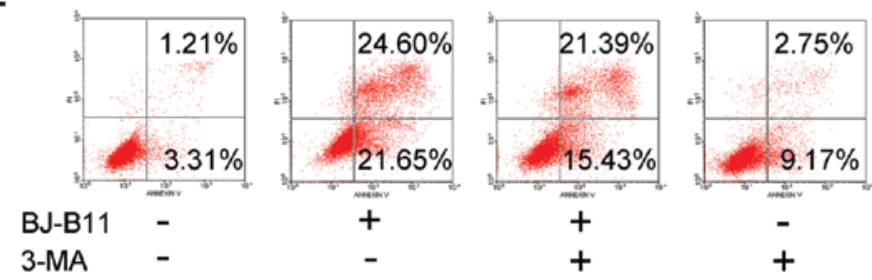

B

LC3

MDC

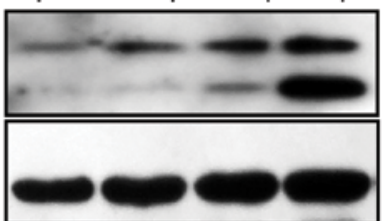

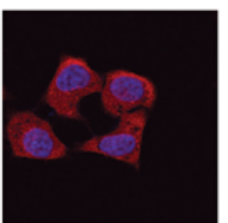

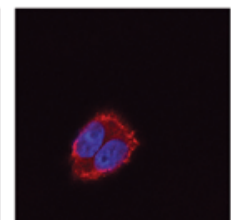

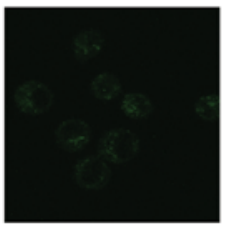

Control

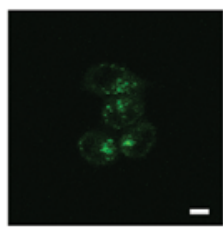

BJ-B11
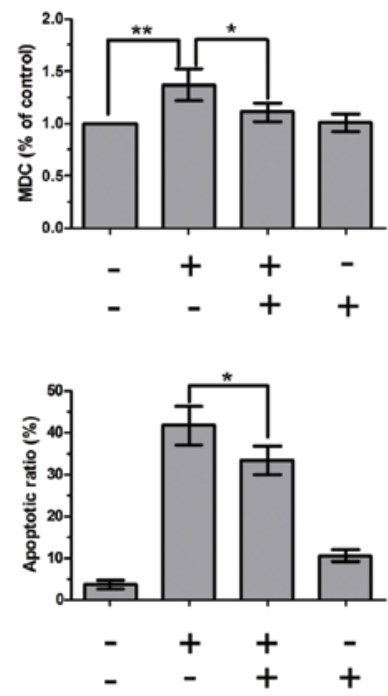

F

BJ-B11 $(0.5 \mu \mathrm{M})$
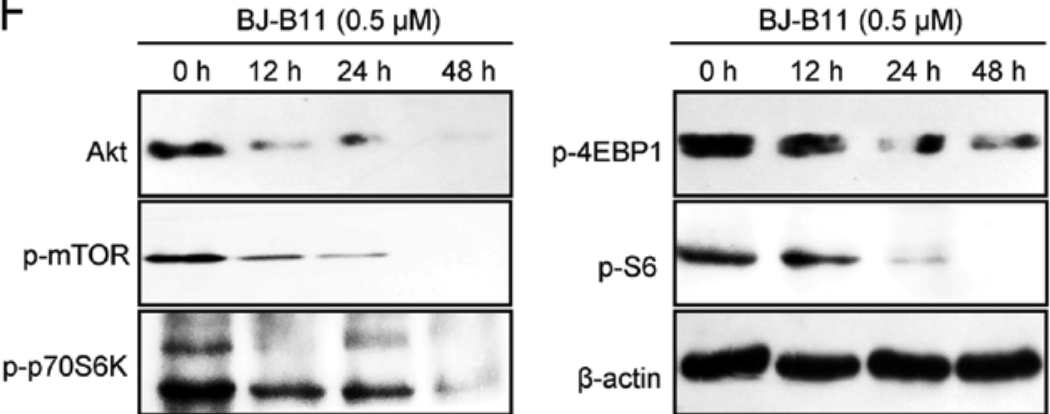

Figure 4. BJ-B11 induces autophagy in Eca-109 cells. (A) TEM ultrastructural analysis of Eca-109 cells treated with $0.5 \mu \mathrm{M}$ BJ-B11 for $48 \mathrm{~h}$, indicating numerous autophagic vacuoles. Scale bars, $5 \mu \mathrm{m}$. (B) Detection of typical punctate LC3 expression pattern (red, upper panels) and autophagic vacuoles using MDC staining (green, lower panels) in Eca-109 cells treated with $0.5 \mu \mathrm{M}$ BJ-B11 for $48 \mathrm{~h}$. Scale bars, $10 \mu \mathrm{m}$. (C) Western blot analysis of LC3 in Eca-109 cells treated with $0.5 \mu \mathrm{M}$ BJ-B11 for the indicated time periods or indicated BJ-B11 for $48 \mathrm{~h}$. $\beta$-actin was used as a loading control. (D) Quantification of MDC-positive vacuoles in Eca-109 cells pretreated with $5 \mathrm{mM} 3-\mathrm{MA} 1 \mathrm{~h}$ prior to treatment with $0.5 \mu \mathrm{M}$ BJ-B11 for $48 \mathrm{~h}$. Values are the mean \pm SD of three independent experiments; ${ }^{*} \mathrm{P}<0.05$ and ${ }^{* *} \mathrm{P}<0.01$. (E) Quantification of apoptotic cells pretreated with $5 \mathrm{mM} 3-\mathrm{MA} 1 \mathrm{~h}$ prior to treatment with $0.5 \mu \mathrm{M} \mathrm{BJ}-\mathrm{B} 11$ for $48 \mathrm{~h}$. Values are the mean \pm SD of three independent experiments; ${ }^{*} \mathrm{P}<0.05$ and ${ }^{* *} \mathrm{P}<0.01$. (F) Western blot analysis of p-mTOR, p-p70S6K, $p-S 6$, and p-4EBP1 in Eca-109 cells treated with $0.5 \mu \mathrm{M}$ BJ-B11 for various time periods. $\beta$-actin was used as a loading control.

\section{Discussion}

Previous studies demonstrated that BJ-B11 displayed less toxicity on normal human cells and more potent anti-tumor activity than the positive control 17-AAG (23). In this study, we showed that
BJ-B11 induced Eca-109 cell cycle arrest, apoptosis, autophagy and cytoskeleton polymerization, resulting in cell death. BJ-B11 induced growth inhibition in Eca-109 cells in a more potent manner than 17-AAG (Fig. 1A and B). BJ-B11 induced G2/M cell cycle arrest in Eca-109 cells, different from the G0/G1 cell 
A
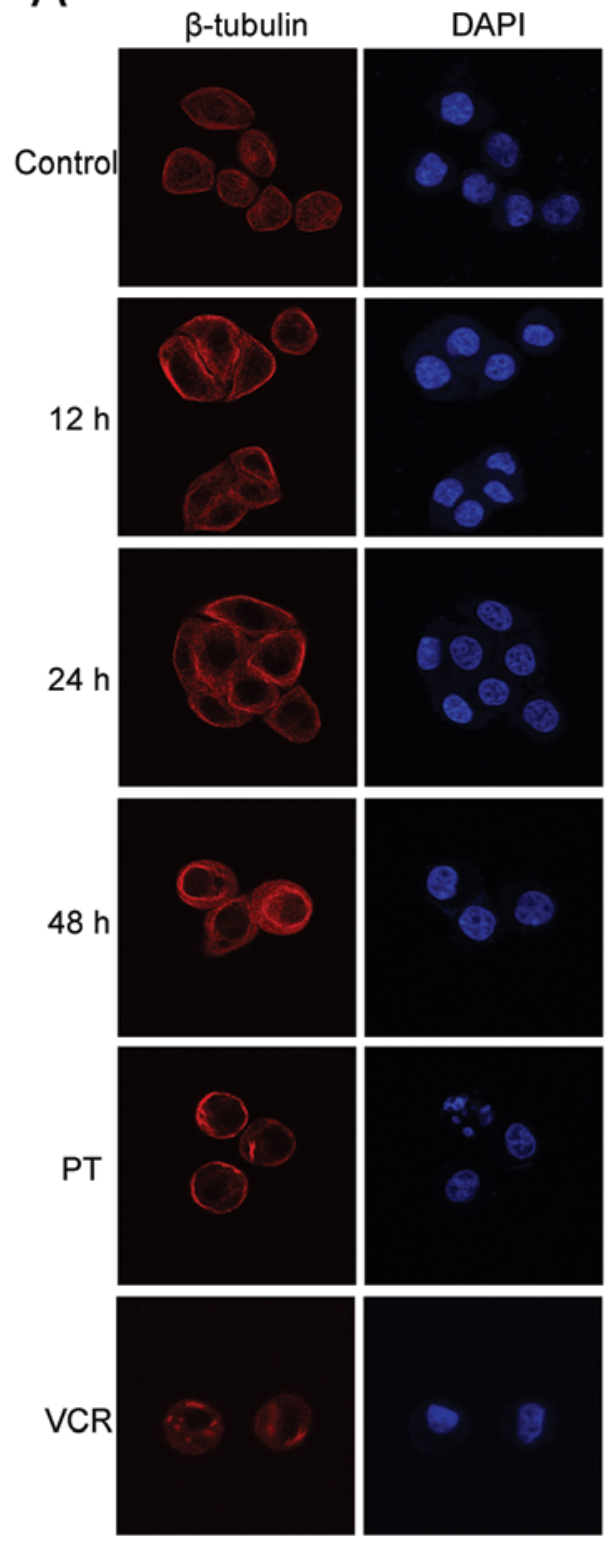

C
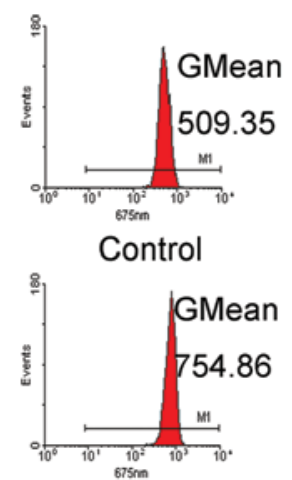

BJ-B11
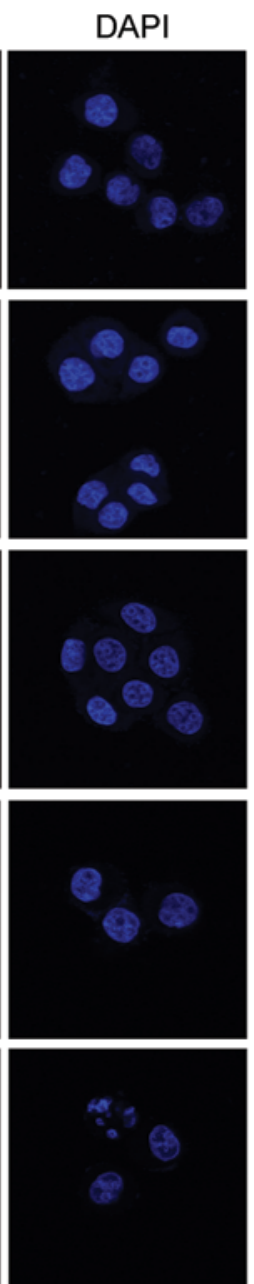
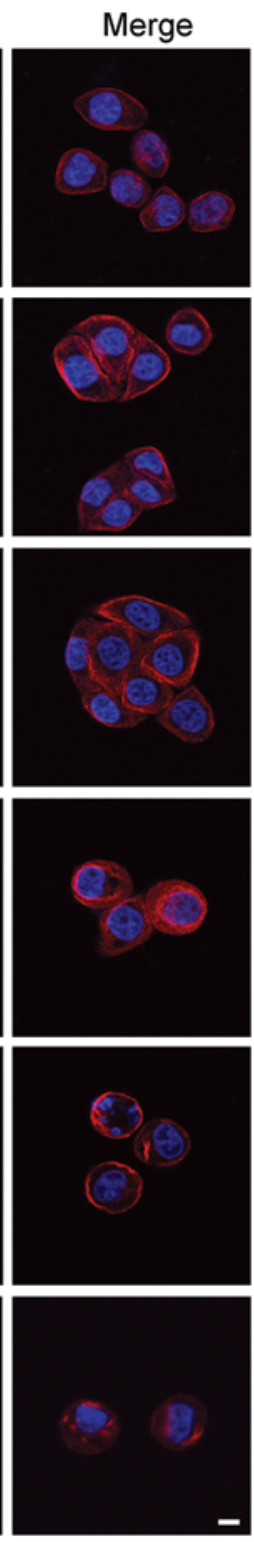

Lat-A

Jas

B-actin
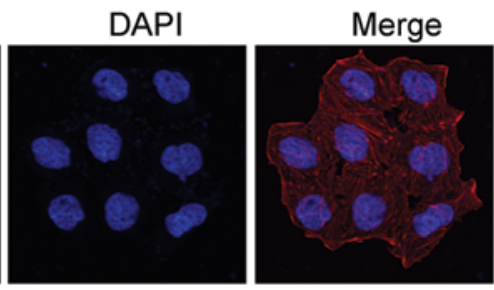

$12 \mathrm{~h}$
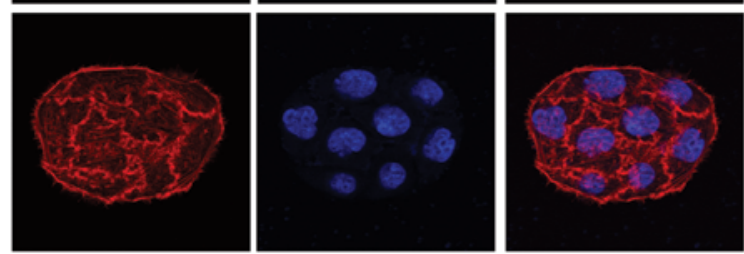

$24 \mathrm{~h}$
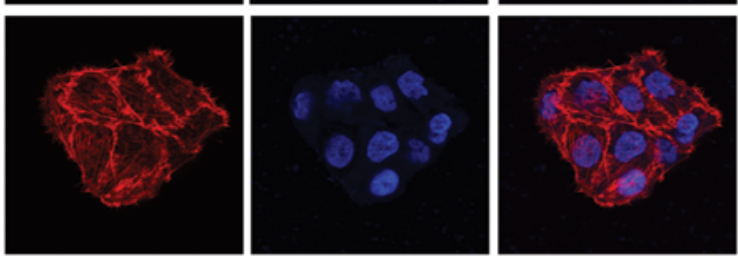

$48 \mathrm{~h}$
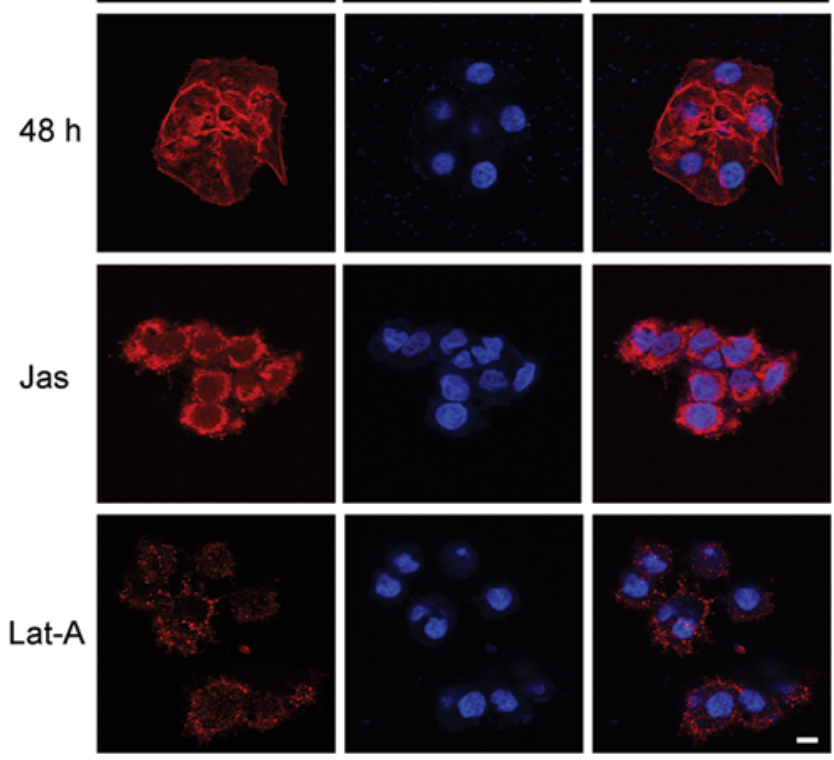

D
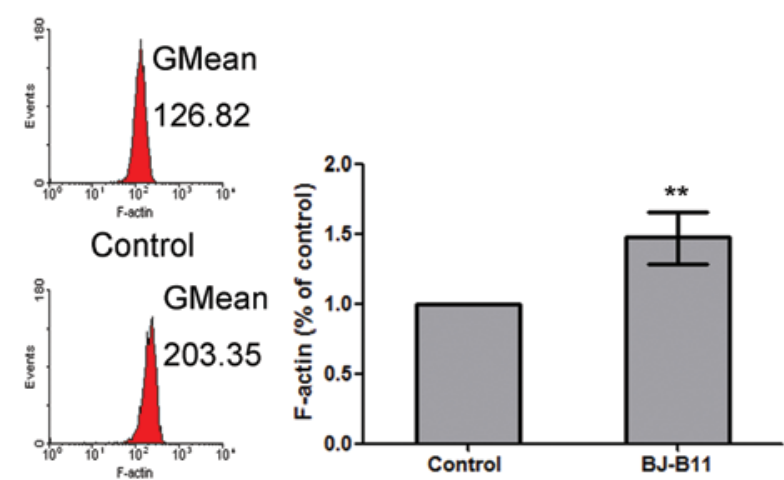

BJ-B11

Figure 5. BJ-B11 induces $\beta$-tubulin and F-actin polymerization in Eca-109 cells. (A) Immunofluorescence images of Eca-109 cells treated with anti- $\beta$-tubulin antibody and then observed by laser scanning confocal microscopy. Cells were either untreated or exposed to $0.5 \mu \mathrm{M}$ BJ-B11 for indicated times. Paclitaxel (PT) and vincristine (VCR) were used as positive or negative control. Scale bars, $10 \mu \mathrm{m}$. (B) Fluorescence images of Eca-109 cells treated with Phalloidin and then observed by laser scanning confocal microscopy. Cells were either untreated or exposed to $0.5 \mu \mathrm{M}$ BJ-B11 for indicated times. Jasplakinolide (Jas) and latrunculin A (Lat-A) were used as positive or negative control. Scale bars, $10 \mu \mathrm{m}$. (C) Quantification of $\beta$-tubulin treated with $0.5 \mu \mathrm{M}$ BJ-B11 for $24 \mathrm{~h}$. Values are the mean $\pm \mathrm{SD}$ of three independent experiments; ${ }^{*} \mathrm{P}<0.05$ and ${ }^{* *} \mathrm{P}<0.01$. (D) Quantification of F-actin treated with $0.5 \mu \mathrm{M}$ BJ-B11 for $24 \mathrm{~h}$. Values are the mean $\pm \mathrm{SD}$ of three independent experiments; ${ }^{*} \mathrm{P}<0.05$ and ${ }^{* *} \mathrm{P}<0.01$. 
cycle arrest in K562 cells (23), suggesting that BJ-B11 might affect the mitosis of Eca-109 cells (Fig. 1C). Thus, the G2/M cell cycle arrest may be responsible for the growth inhibition of Eca-109 cells induced by BJ-B11.

BJ-B11 induced apoptosis in Eca-109 cells, characterized by altered cell morphology, DNA fragment, caspase activation and PARP cleavage (Fig. 2). It is known that apoptosis is regulated by two major pathways: the mitochondrial pathway and death receptor pathway (33). Mitochondria play a central role in determining cell survival or death in response to diverse stimuli (34). The mitochondrial dysfunction is characterized by the production of ROS, release of cytochrome $c$, and disruption of MMP, and the mitochondrial apoptotic pathway is associated with caspase activation (35). The generation of ROS damages the mitochondria which may result in apoptosis or autophagy $(36,37)$. Cytochrome $c$ release activates caspase-mediated apoptosis pathway. In the present study, the time-dependent production of ROS, release of cytochrome $c$ into the cytosol and depletion of MMP were observed in BJ-B11-treated Eca-109 cells (Fig. 3). Thus, BJ-B11 may induce mitochondrial-mediated apoptosis in Eca-109 cells.

We provide evidence that BJ-B11 also induced autophagy in Eca-109 cells. At present, the precise molecular mechanism that switches between apoptosis and autophagy needs to be further investigated. Autophagy and apoptosis can be induced in response to different cellular stresses, and they can act in synergy or in a mutually exclusive manner (38). In our study, pretreatment of Eca-109 cells with 3-MA decreased the fluorescence intensity of MDC-positive vacuoles and the ratio of apoptotic cells induced by BJ-B11, indicating that autophagy promoted apoptosis induced by BJ-B11 (Fig. 4D and E).

It has been suggested that Akt/mTOR/p70S6K pathway negatively regulate autophagy in cancer cells (39). Our results suggest that BJ-B11 may induce autophagy via the inhibition of $\mathrm{Akt} / \mathrm{mTOR} / \mathrm{p} 70 \mathrm{~S} 6 \mathrm{~K}$ pathway, and that BJ-B11-induced autophagy may be associated with Akt degradation in a mechanism dependent on Hsp90 inhibition and Akt-mediated inhibition of mTOR activity. This is consistent with several other reports (39-41).

It has been suggested that microtubules are crucial in the development and maintenance of cell shape, the transportation of vesicles and mitochondria throughout the cells, and in the cell signaling, division and mitosis (42). Actin is the major component of the cytoskeleton and also plays many important roles in cell growth, division, motility, signal transduction, cell- cell adhesion, and wound-healing processes (43). In recent years, increasing numbers of compounds have been reported to interact with the microtubule and actin cytoskeleton, including paclitaxel, vincristine, colchicines, latrunculin A, jasplakinolide and azadirachtin A (44-46). Paclitaxel is reported as an inducer of G2/M arrest, and causes caspase-8-induced apoptosis (47). Paclitaxel can also induce apoptosis and autophagy in v-Haras-transformed fibroblasts (48). In our study, BJ-B11 induced $\beta$-tubulin and F-actin polymerization at 12, 24 and $48 \mathrm{~h}$, which might be responsible for the G2/M cell cycle arrest, apoptosis, and autophagy $(31,32)$.

In conclusion, this study provides the first evidence that BJ-B11 induces G2/M cell cycle arrest, apoptosis, autophagy and polymerization of cytoskeleton in Eca-109 cells. These findings may facilitate future investigations on the potential of
BJ-B11 as a targeted therapy agent for the treatment of human esophageal squamous carcinoma.

\section{Acknowledgements}

This study was supported by Grants from the IndustryAcademia-Research Demonstration Base of Guangdong Higher Education Institutes (Innovative Culturing Base of Graduates) (no. 2010B091000013), the Twelfth Five-Year National Science and Technology Support Program (no. 2012BAI29B06), the National Natural Science Foundation of China (no. 81001449), and the Natural Science Foundation of Guangdong Province of China (10451063201005506).

\section{References}

1. Porter JR, Fritz CC and Depew KM: Discovery and development of Hsp90 inhibitors: a promising pathway for cancer therapy. Curr Opin Chem Biol 14: 412-420, 2010.

2. Mahalingam D, Swords R, Carew JS, Nawrocki ST, Bhalla K and Giles FJ: Targeting HSP90 for cancer therapy. Br J Cancer 100: 1523-1529, 2009.

3. Lu X, Xiao L, Wang L and Ruden DM: Hsp90 inhibitors and drug resistance in cancer: The potential benefits of combination therapies of Hsp90 inhibitors and other anti-cancer drugs. Biochem Pharmacol 83: 995-1004, 2012.

4. Oude Munnink TH, Korte MA, Nagengast WB, et al: (89Zr-trastuzumab PET visualises HER2 downregulation by the HSP90 inhibitor NVP-AUY922 in a human tumour xenograft. Eur J Cancer 46: 678-684, 2010.

5. Eccles SA, Massey A, Raynaud FI, et al: NVP-AUY922: a novel heat shock protein 90 inhibitor active against xenograft tumor growth, angiogenesis, and metastasis. Cancer Res 68: 2850-2860, 2008.

6. Whitesell L and Lindquist SL: HSP90 and the chaperoning of cancer. Nat Rev Cancer 5: 761-772, 2005.

7. Xu C, Liu J, Hsu LC, Luo Y, Xiang R and Chuang TH: Functional interaction of heat shock protein 90 and Beclin 1 modulates Toll-like receptor-mediated autophagy. FASEB J 25: 2700-2710, 2011.

8. Palacios C, Martin-Perez R, Lopez-Perez AI, Pandiella A and Lopez-Rivas A: Autophagy inhibition sensitizes multiple myeloma cells to 17-dimethylaminoethylamino-17-demethoxygeldanamycin-induced apoptosis. Leuk Res 34: 1533-1538, 2010.

9. Gozuacik D and Kimchi A: Autophagy as a cell death and tumor suppressor mechanism. Oncogene 23: 2891-2906, 2004.

10. Gou X, Ru Q, Zhang H, et al: HAb18G/CD147 inhibits starvationinduced autophagy in human hepatoma cell SMMC7721 with an involvement of Beclin 1 down-regulation. Cancer Sci 100: 837-843, 2009.

11. Rami A and Kogel D: Apoptosis meets autophagy-like cell death in the ischemic penumbra: two sides of the same coin? Autophagy 4: 422-426, 2008.

12. Kondo Y, Kanzawa T, Sawaya R and Kondo S: The role of autophagy in cancer development and response to therapy. Nat Rev Cancer 5: 726-734, 2005.

13. Solit DB and Chiosis G: Development and application of Hsp90 inhibitors. Drug Discov Today 13: 38-43, 2008.

14. Li Y, Zhang T, Schwartz SJ and Sun D: New developments in Hsp90 inhibitors as anti-cancer therapeutics: mechanisms, clinical perspective and more potential. Drug Resist Updat 12: 17-27, 2009.

15. Taldone T, Sun W and Chiosis G: Discovery and development of heat shock protein 90 inhibitors. Bioorg Med Chem 17: 2225-2235, 2009.

16. Wang SX, Ju HQ, Liu KS, et al: SNX-2112, a novel Hsp90 inhibitor, induces G2/M cell cycle arrest and apoptosis in MCF-7 cells. Biosci Biotechnol Biochem 75: 1540-1545, 2011.

17. Liu KS, Ding WC, Wang SX, et al: The heat shock protein 90 inhibitor SNX-2112 inhibits B16 melanoma cell growth in vitro and in vivo. Oncol Rep 27: 1904-1910, 2012.

18. Okawa Y, Hideshima T, Steed P, et al: SNX-2112, a selective Hsp90 inhibitor, potently inhibits tumor cell growth, angiogenesis, and osteoclastogenesis in multiple myeloma and other hematologic tumors by abrogating signaling via Akt and ERK. Blood 113: 846-855, 2009. 
19. Jin L, Xiao CL, Lu CH, et al: Transcriptomic and proteomic approach to studying SNX-2112-induced K562 cells apoptosis and anti-leukemia activity in K562-NOD/SCID mice. FEBS Lett 583: 1859-1866, 2009.

20. Liu KS, Liu H, Qi JH, et al: SNX-2112, an Hsp90 inhibitor, induces apoptosis and autophagy via degradation of Hsp90 client proteins in human melanoma A-375 cells. Cancer Lett 318: 180-188, 2012.

21. Zhai QQ, Gong GQ, Liu Z, et al: Preclinical pharmacokinetic analysis of SNX-2112, a novel Hsp90 inhibitor, in rats. Biomed Pharmacother 65: 132-136, 2011.

22. Zhai QQ, Gong GQ, Luo Y, et al: Determination of SNX-2112, a selective Hsp90 inhibitor, in plasma samples by high-performance liquid chromatography and its application to pharmacokinetics in rats. J Pharm Biomed Anal 53: 1048-1052, 2010.

23. Ju HQ, Wang SX, Xiang YF, et al: BJ-B11, a novel Hsp90 inhibitor, induces apoptosis in human chronic myeloid leukemia K562 cells through the mitochondria-dependent pathway. Eur J Pharmacol 666: 26-34, 2011.

24. Ju HQ, Xiang YF, Xin BJ, et al: Synthesis and in vitro anti-HSV-1 activity of a novel Hsp90 inhibitor BJ-B11. Bioorg Med Chem Lett 21: 1675-1677, 2011.

25. Kumar S: Caspase function in programmed cell death. Cell Death Differ 14: 32-43, 2007.

26. Green DR and Kroemer G: The pathophysiology of mitochondrial cell death. Science 305: 626-629, 2004.

27. Mizushima N, Yoshimori T and Levine B: Methods in mammalian autophagy research. Cell 140: 313-326, 2010.

28. Shinojima N, Yokoyama T, Kondo Y and Kondo S: Roles of the $\mathrm{Akt} / \mathrm{mTOR} / \mathrm{p} 70 \mathrm{~S} 6 \mathrm{~K}$ and ERK1/2 signaling pathways in curcumin-induced autophagy. Autophagy 3: 635-637, 2007.

29. Viola G, Bortolozzi R, Hamel E, et al: MG-2477, a new tubulin inhibitor, induces autophagy through inhibition of the Akt/ mTOR pathway and delayed apoptosis in A549 cells. Biochem Pharmacol 83: 16-26, 2012.

30. McElligott AM, Maginn EN, Greene LM, et al: The novel tubulin-targeting agent pyrrolo-1,5-benzoxazepine-15 induces apoptosis in poor prognostic subgroups of chronic lymphocytic leukemia. Cancer Res 69: 8366-8375, 2009.

31. Tang YA, Wen WL, Chang JW, et al: A novel histone deacetylase inhibitor exhibits antitumor activity via apoptosis induction, F-actin disruption and gene acetylation in lung cancer. PLoS One 5: e12417, 2010.

32. Hwang JH, Takagi M, Murakami H, Sekido Y and Shin-ya K: Induction of tubulin polymerization and apoptosis in malignant mesothelioma cells by a new compound JBIR-23. Cancer Lett 300: 189-196, 2011.

33. Hogstrand K, Hejll E, Sander B, Rozell B, Larsson LG and Grandien A: Inhibition of the intrinsic but not the extrinsic apoptosis pathway accelerates and drives MYC-driven tumorigenesis towards acute myeloid leukemia. PLoS One 7: e31366, 2012.
34. Adams JM and Cory S: Life-or-death decisions by the Bcl-2 protein family. Trends Biochem Sci 26: 61-66, 2001.

35. Wang YC, Lee CM, Lee LC, et al: Mitochondrial dysfunction and oxidative stress contribute to the pathogenesis of spinocerebellar ataxia type 12 (SCA12). J Biol Chem 286: 21742-21754, 2011.

36. Nicolau-Galmes F, Asumendi A, Alonso-Tejerina E, et al: Terfenadine induces apoptosis and autophagy in melanoma cells through ROS-dependent and -independent mechanisms. Apoptosis 16: 1253-1267, 2011.

37. Liu B, Cheng Y, Zhang B, Bian HJ and Bao JK: Polygonatum cyrtonema lectin induces apoptosis and autophagy in human melanoma A375 cells through a mitochondria-mediated ROS-p38p53 pathway. Cancer Lett 275: 54-60, 2009.

38. Eisenberg-Lerner A, Bialik S, Simon HU and Kimchi A: Life and death partners: apoptosis, autophagy and the cross-talk between them. Cell Death Differ 16: 966-975, 2009.

39. Saiki S, Sasazawa Y, Imamichi Y, et al: Caffeine induces apoptosis by enhancement of autophagy via PI3K/Akt/mTOR/p70S6K inhibition. Autophagy 7: 176-187, 2011.

40. Takeuchi H, Kondo Y, Fujiwara K, et al: Synergistic augmentation of rapamycin-induced autophagy in malignant glioma cells by phosphatidylinositol 3-kinase/protein kinase B inhibitors. Cancer Res 65: 3336-3346, 2005.

41. Degtyarev M,De Maziere A, Orr C, et al: Akt inhibition promotes autophagy and sensitizes PTEN-null tumors to lysosomotropic agents. J Cell Biol 183: 101-116, 2008.

42. Shen L, Xu W, Li A, Ye J and Zhou J: JWA enhances AsO-induced tubulin polymerization and apoptosis via p38 in HeLa and MCF-7 cells. Apoptosis 16: 1177-1193, 2011.

43. Moon SS, Rahman AA, Kim JY and Kee SH: Hanultarin, a cytotoxic lignan as an inhibitor of actin cytoskeleton polymerization from the seeds of Trichosanthes kirilowii. Bioorg Med Chem 16: 7264-7269, 2008

44. Canta A, Chiorazzi A and Cavaletti G: Tubulin: a target for antineoplastic drugs into the cancer cells but also in the peripheral nervous system. Curr Med Chem 16: 1315-1324, 2009.

45. Allingham JS, Klenchin VA and Rayment I: Actin-targeting natural products: structures, properties and mechanisms of action. Cell Mol Life Sci 63: 2119-2134, 2006.

46. Fenteany G and Zhu S: Small-molecule inhibitors of actin dynamics and cell motility. Curr Top Med Chem 3: 593-616, 2003.

47. Mielgo A, Torres VA, Clair K, Barbero S and Stupack DG: Paclitaxel promotes a caspase 8-mediated apoptosis through death effector domain association with microtubules. Oncogene 28: 3551-3562, 2009.

48. Eum KH and Lee M: Crosstalk between autophagy and apoptosis in the regulation of paclitaxel-induced cell death in v-Ha-rastransformed fibroblasts. Mol Cell Biochem 348: 61-68, 2011. 